\title{
ON THE HYERS-ULAM-RASSIAS STABILITY OF AN $n$-DIMENSIONAL PEXIDERIZED QUADRATIC EQUATION
}

\author{
KIL-Woung Jun, JAE-HyeOng BAE AND YANG-Hi LeE
}

Abstract. In this paper we prove the stability of an $n$-dimensional Pexiderized quadratic equation

$f_{1}\left(\sum_{i=1}^{n} x_{i}\right)+\sum_{1 \leqslant i<j \leqslant n} f_{\alpha(i, j)}\left(x_{i}-x_{j}\right)=n \sum_{i=1}^{n} f_{\beta(i)}\left(x_{i}\right)$ in the spirits of Hyers, Ulam and Rassias.

Mathematics subject classification (2000): 39B72, 47H15. equation.

Key words and phrases: Quadratic function, Hyers-Ulam-Rassias stability, Pexiderized Euler-Lagrange

\section{REFERENCES}

[1] C. Borelli AND G. L. ForTI, On a general Hyers-Ulam-stability result, Internat. J. Math. Math. Sci. 18 (1995), 229-236.

[2] P. W. CHOLEWA, Remarks on the stability of functional equations, Aequationes Math. 27 (1984), 76-86.

[3] S. CZERWIK, On the stability of the quadratic mapping in normed spaces, Abh. Math. Sem. Univ. Hamburg. 62 (1992), 59-64.

[4] P. GăVRUTA, A generalization of the Hyers-Ulam-Rassias stability of approximately additive mappings, J. Math. Anal. and Appl. 184 (1994), 431-436.

[5] D. H. HYERS, On the stability of the linear functional equation, Proc. Nat. Acad. Sci. U.S.A. 27 (1941), 222-224.

[6] D. H. Hyers, G. ISAC AND TH. M. RASsias, "Stability of Functional Equations in Several Variables", Birkhäuser (1998).

[7] D. H. Hyers AND Th. M. RASsiAs, Approximate homomorphisms, Aeq. Math. 44 (1992), $125-153$.

[8] K. -W. JUN AND Y. -H. LEE, On the Hyers-Ulam-Rassias stability of a generalized quadratic equation, Bull. Korean Math. Soc. 38 (2001), 261-272.

[9] K. -W. Jun AND Y. -H. LEE, On the Hyers-Ulam-Rassias stability of a Pexiderized quadratic inequality, Math. Ineq. Appl. 4 (2001), 93-118.

[10] K. -W. Jun, D.-S. SHIN AND B. -D. KIM, On Hyers-Ulam-Rassias stability of the pexider equation, J. Math. Anal. Appl. 239 (1999), 20-29.

[11] S.-M. Jung, On the Hyers-Ulam stability of the functional equations that have the quadratic property, J. Math. Anal. Appl. 222 (1998), 126-137.

[12] S.-M. Jung, On the Hyers-Ulam-Rassias stability of a quadratic functional equation, J. Math. Anal. Appl. 232 (1999), 384-393.

[13] PL. KannAPPAN, Quadratic functional equation and inner product spaces, Results Math. 27 (1995), 368-372.

[14] Y. -H. LEE AND K. -W. JUN, A generalization of the Hyers-Ulam-Rassias stability of Pexider equation, J. Math. Anal. Appl. 246 (2000), 627-638.

[15] Y. -H. LEE AND K. -W. JUN, A note on the Hyers-Ulam-Rassias stability of Pexider equation, J. Korean Math. Soc. 37 (2000), 111-124.

[16] J. M. RASSIAS, On the stability of the Euler-Lagrange functional equation, Chinese J. Math. 20 (1992), 185-190. 
[17] Th. M. Rassias, On the stability of the linear mapping in Banach spaces, Proc. Amer. Math. Soc. 72 (1978), 297-300.

[18] TH. M. Rassias, Stability and set-valued functions, in: Analysis and Topology, World Scientific Publ. Co., 1988, pp. 585-614.

[19] TH. M. RASSIAS, On the stability of the quadratic functional equation and its applications, Studia Univ. "Babes-Bolyai" XLIII (3) (1998), 89-124.

[20] TH. M. Rassias, Functional equations and inequalities, Kluwer Academic Publishers, Dordrecht, 2000.

[21] TH. M. RASSIAS, On the stability of functional equations and a problem of Ulam, Acta Math. 62 (2000), 23-130.

[22] TH. M. Rassias, On the stability of functional equations in Banach spaces, J. Math. Anal. Appl. 251 (2000), 264-284.

[23] TH. M. Rassias, On the stability of the quadratic functional equation, Mathematica, XLV(2) (2000), 77-114.

[24] F. SKoF, Proprietà locali e approssimazione di operatori, Rend. Sem. Mat. Fis. Milano 53 (1983), 113-129.

[25] S. M. Ulam, “Problems in Modern Mathematics”, Chap. VI, Wiley, New York, 1960. 